\title{
Condition of Students' Mathematical Reasoning Abilities Based on Their Ability to Argue
}

\author{
Arlina Trie Cahyono a, Susiswo ${ }^{\text {b,* }}$, Tjang Daniel Chandra ${ }^{c}$ \\ ${ }^{a, b, c}$ Mathematics Departement, Uiversitas Negeri Malang, \\ Semarang Street, Number 5, Malang, East Java, Indonesia \\ *Corresponding author's e-mail: susiswo.fmipa@um.ac.id
}

\begin{abstract}
This study aims to reveal the condition of students' reasoning abilities based on the way students argue. This research uses a qualitative-descriptive approach. The subjects in this study were 3 students of junior high school with high reasoning abilities and 3 students with low reasoning abilities who viewed the reasoning ability scores when providing problem solving solutions on the written test. The data obtained in this study were in the form of students' written test scores and the results of student interviews. Interviews were conducted to bring up students 'ability to argue that describe and reveal the condition of students' reasoning abilities in the process of solving problems. The results of students 'arguments are analyzed and adjusted to the model of StephenToulmin's argument which reveals that there are 6 components of the argumentation to show the seriousness of students in arguing in order to obtain valid argument results to assess students' reasoning abilities. The arguments from students succeeded in uncovering 4 conditions that describe the conditions of students' mathematical reasoning abilities. These conditions are: 1) Students who show high reasoning ability in written tests and are able to show their reasoning process in the arguments that are brought up, 2) Students who show low reasoning abilities in written tests but are able to show their reasoning processes in the arguments that are brought up, 3) Students which shows a high reasoning ability in a written test but have not been able to demonstrate the reasoning process in the arguments that are brought up, and 4) Students who show a low reasoning ability in a written test and have not been able to demonstrate their reasoning process in the arguments that are brought up.
\end{abstract}

\section{Introduction}

Reasoning is an important thing that needs to be considered in understanding a problem, both daily life problems and math problems. Therefore reasoning is indispensable in learning mathematics. The importance of reasoning in learning mathematics makes good students' reasoning 
abilities one of the goals to be achieved in mathematics learning [7]. In the reasoning done by students, it will be seen that the process of students in thinking to work on a given problem. This is in accordance with the objectives of the curriculum that is applied in Indonesia. In the current 2013 curriculum, learning emphasizes a scientific approach and character that emphasizes the assessment of process characteristics. In the process of reasoning students, the ability of students in the process of reasoning can show their scientific ability and the process of understanding students [5]. Apart from the 2013 curriculum, the objectives of self-learning are also revealed in NCTM. The learning objectives are: 1) Understanding mathematical concepts, 2) Using reasoning on patterns and characteristics in solving problems, 3) Solving problems and having the ability to understand problems, 4) Communicating work results, 5) Having an attitude of appreciating the usefulness of mathematics [8].

This important mathematical reasoning ability of students must have problems that arise in it. One of the problems that exist is, the reasoning ability of students in Indonesia is currently classified in the low category. This low ability is often found because students are less able to understand problems so they make mistakes in the process of solving math problems [7]. Students' reasoning problems found in reasoning abilities are not only felt by students, but also by the teacher. Mathematical reasoning problems that often arise in students are the inability of students to write down the information needed to solve problems and the difficulties experienced by students in writing and choosing mathematical problem-solving strategies that are given in detail in the written test. This results in students being considered not doing a good reasoning process by the teacher because they do not write down in detail the steps of solving the given questions [10]. Another student reasoning ability problem that is often encountered in mathematics learning activities is that students only follow the procedures from the teacher without understanding the concept of the material given. This results in students being unable to do reasoning if the mathematical problems given are changed. In addition, the problem of assessing reasoning abilities that is often encountered is that teachers are more likely to assess students' reasoning abilities based on the results of their written tests only. Teachers often conclude or assess students' reasoning abilities only from their written results. This assessment is considered less valid because there are students who have the ability to communicate their reasoning skills in writing which are not good, but can communicate their ideas verbally well [1].

The problem of reasoning ability experienced by students and teachers requires teachers to have other ways to find out students' reasoning abilities. The importance of this method is owned by the teacher because it is to validate the reasoning abilities of students with good reasoning abilities but 
cannot communicate in writing. One way that can be used to more validly determine students' reasoning abilities is to reveal the ability of students to argue and be accountable for their work [3]. Students when arguing can show students' processes in thinking and reasoning. In the argumentation process, students will show rebuttals and reasons in defending the answers expressed. This shows the understanding of concepts and thought processes that they have to maintain answers and solve problems given [3]. The arguments presented by students are the result of the student's process of gathering argument components and building logical arguments. One component that is currently known is the component expressed by Stephen Toulmin [12]. The components of the argument are claims, evidence, warrant, backing, qualifier, and rebuttal [13]. In the argumentation component expressed by Stephen Tulmin, it can help in expressing the reasoning abilities of students more validly. This component can help see whether the arguments given by students are the result of a reasoning process, or just arguments without a basis of reasoning [13]. The first relevant research is research conducted by Iga Oktiana and Ratu Ilma in 2019 entitled "Student Mathematical Reasoning in Learning Number Patterns Using PMRI and LSLC". The results shown in further research revealed that by using the PMRI and LSLC approaches to see students' reasoning abilities, students had already shown mathematical reasoning abilities. Students are able to show conjecture, but for indicators to draw logical conclusions students still cannot show it well. So the researchers concluded that in the number pattern material the students 'abilities were able to bring up students' reasoning indicators, although not all [10]. The similarity of this research with previous research on the material chosen to show students' reasoning abilities. While the difference is in the method for showing student reasoning. In their research, Oktiana and Ratu used the PMRI and LSLC approaches to demonstrate their reasoning abilities. Meanwhile, in this study using student arguments to show students' reasoning abilities [10].

Mathematical material that is taught and requires reasoning in the process of its completion is number pattern material. This is because, when students carry out the process of solving number pattern problems, students are asked to carry out the generalization process. Determining the generality requires good reasoning skills so that students are required to have good reasoning skills [13]. The importance of reasoning abilities that students have and are known to the teacher results in a valid reasoning ability assessment that needs to be done in mathematics learning. In previous researchers, researchers have conducted a study of students' reasoning abilities. In previous studies, researchers emphasized the assessment of students 'reasoning abilities on the results of students' written tests. Previous researchers in assessing students 'reasoning abilities had not paid attention to 
students' thinking processes as seen from verbal reasons. From these problems, this study conducted an analysis using student arguments that showed valid students' reasoning abilities [4].

\section{Research Methods}

This research was conducted with a qualitative approach. This study shows students' mathematical reasoning abilities in terms of their argumentative abilities. The students' argumentation skills are adjusted to the argumentation component of Stephen Toulmin to determine the validity of the arguments given. Because the research was carried out on individuals in depth by examining students 'argumentative abilities to determine students' mathematical reasoning abilities, this type of research is a descriptive study.

In this research, it was carried out by going through 4 steps or stages. The stages taken are 1) the observation stage, 2) the implementation stage, 3) the data analysis stage and 4) the report writing stage. The location of the research is SMP Aisyiyah Boarding School Malang. The subjects of the study were 6 students. Subjects were selected based on the results of their written test assessments. Students with the highest and lowest scores on each question number were the subjects in this study.

The instruments used in this study were written test question sheets 1), written test sheets 2 , interview guidelines, indicators of students' written mathematical reasoning abilities, indicators of students' reasoning abilities in terms of students' argumentation abilities. This study uses two steps in the data collection carried out. The first step in data collection was to conduct a written test. The second step was to conduct interviews to bring up students' arguments. In this study, the procedure used in collecting data was initiated by giving written tests which were used to determine students' written reasoning abilities. Then the collection was continued with an interview to determine the student's reasoning process which showed a more valid reasoning ability. While the data analysis technique used in this study was to adjust the results of students 'reasoning abilities with indicators of students' mathematical reasoning abilities in terms of their arguments. Indicators are used to assess students' mathematical reasoning abilities.

\section{Results and Discussion}

This research was conducted to reveal students 'mathematical reasoning abilities in terms of students' ability to argue. The research was conducted by giving written test questions to 20 students of class VIII SMP Aisyiyah Boarding School Malang. Based on the results of the tests carried out, it was obtained data on students who had the highest and lowest assessment scores on the written test. 


\section{Description of Students' Mathematical Reasoning Ability in Terms of Argumentation Ability According to Stephen Toulmin's Argumentation Model}

Student $\mathrm{H}$ is a student with high reasoning abilities Figure 1 is a picture that shows the work of student $\mathrm{H}$ in solving question number 1.

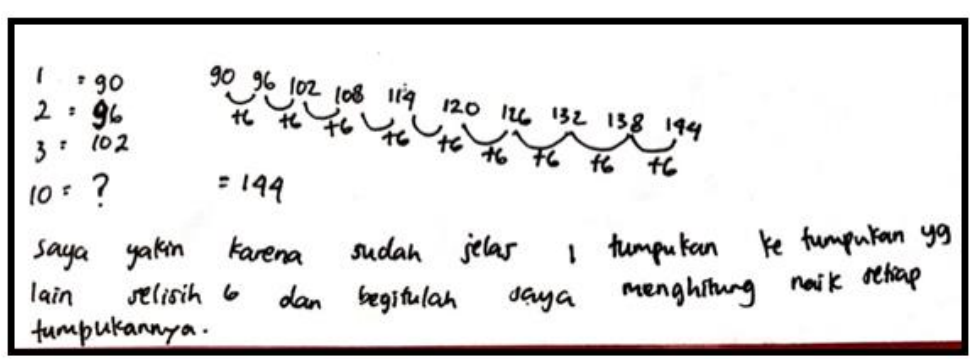

Figure 1. Student work results $\mathrm{H}$

Based on Figure 1 is the work of student $\mathrm{H}$. Student $\mathrm{H}$ is a student with a high score of reasoning ability. This is because students are considered to be able to understand the number pattern problems given. Based on the results of the students' written tests, it can be seen that student $\mathrm{H}$ reasoned inductively by understanding patterns and making certain categories. Student $\mathrm{H}$ starts working on the problem by writing down the information that is known and being asked about the question. This initial step shows that students meet the first indicator of reasoning ability, namely being able to understand question information. Student $\mathrm{H}$ completed it by using the formula manually. Students add one by one from the previously known patterns. The steps of the student in using the pattern found show that the student meets the indicator of the third reasoning ability, which is to determine that the problem can be done using the Student's pattern rules which describe one by one the pattern he finds and add 6 for the next pattern shows that the student meets the fifth reasoning indicator, namely using the identification results questions to plan strategies in solving problems. In working on question number 1 students did not generalize the pattern. This shows that students have not been able to meet the 6th and 7th indicators properly. The results of student work show that students are able to meet the 8th and 9th indicators well which is shown by the student's ability to solve problems well using the method she chose.

The results of the interview above were then analyzed using the argument scoring guidelines according to the Toulmin argumentation model. In accordance with the results of the analysis of students' written work, the results of the argumentation analysis showed that the students did the reasoning process inductively. Claims from the final results and how to solve the questions given by students are right to be the solution to the questions given. Students who are able to claim how to solve problems correctly show students' reasoning abilities in predicting the problem solving process 
that is given well. The data that is used as the basis for making claims is also relevant and used in the problem-solving process. Students are also able to provide assumptions to show the relationship between the data obtained and the claims given. Both of these abilities show that in solving problems, students carry out a reasoning process, namely analyzing the mathematical situation contained in the problem. The reasons given by students can also strengthen the assumptions given. Student $\mathrm{H}$ is also able to strengthen the conclusions given by providing rebuttals in defending the answer when the researcher gives an opinion that shows a counter attitude to the student's claim. In solving the questions students have not been able to generalize about existing patterns in general, but students are able to show reasons why students do not generalize existing patterns with the right data and evidence. This shows that student $\mathrm{H}$ carried out a reasoning process in solving the number pattern problems given. Based on the scores obtained from the results of student H's argumentation analysis, it can be concluded that student $\mathrm{H}$ has high reasoning abilities.

AN students are students with low written reasoning skills. AN students' reasoning ability is classified as low based on the results of students' written tests which are adjusted to the guidelines for scoring students' reasoning abilities. Figure 2 below is the result of student A's written test.

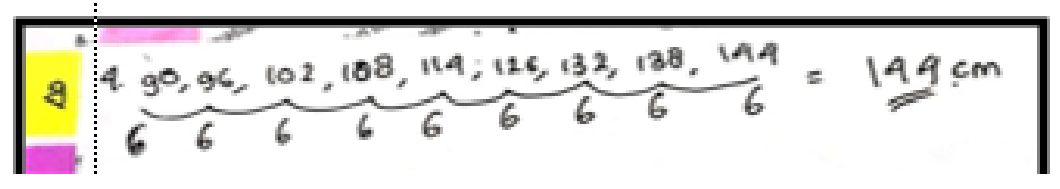

Figure 2. Student work results AN

Figure 2 shows the work results of AN students. AN student work results show a tendency that students reason inductively. AN student work results are then analyzed using indicators of students' written reasoning abilities. The completion process given shows that AN students have not been able to write down the information that is known and asked in the questions. This results in students being deemed not to have good reasoning skills.

The results of the interview above were then analyzed using the guidelines for the students' argumentation skills. The results of the interview analysis conducted showed that AN students were able to provide accurate claims to determine the solution for the completion steps and the final results of the questions given. The claim given shows that AN students fulfill the aspect of ability to provide accurate claims. Students who can provide accurate claims show the student's ability to predict the problem solving process. This ability shows that AN students carry out a reasoning process in solving questions. Claims given by AN students are supported by data collected from the information contained in the questions properly. The data obtained and able to be used to support the statement 
given fulfills the coverage and quality aspects of the data. The assumptions and reasons given by students to connect the data and claims made can strengthen the claims given. The student's ability to provide data that supports and is able to provide assumptions shows that students are able to analyze the mathematical situation on the questions. Student rebuttals to strengthen claims when researchers provide sentences that contradict their claims can also provide truth in the claims made. In solving the number pattern problems given, students do not carry out a generalization process which shows students reasoning to determine the solution to the problem. However, in the interview process, AN students were able to explain the process in choosing a solution that was used appropriately and accompanied by data and assumptions that were able to support the claim for a given solution. The ability of students to provide reasons, rebuttals, and limitations in arguing shows that students are also able to provide valid arguments in the process of reasoning to solve a given number pattern problem. Based on the results of the student's argumentation analysis adjusted to the Toulmin argumentation model, AN students have high scores of reasoning abilities. A high score of AN students can conclude that the reasoning ability of AN students is high.

IA students are students with low reasoning abilities based on their written test scores. The following are the results of the IA students' work for question number 2.

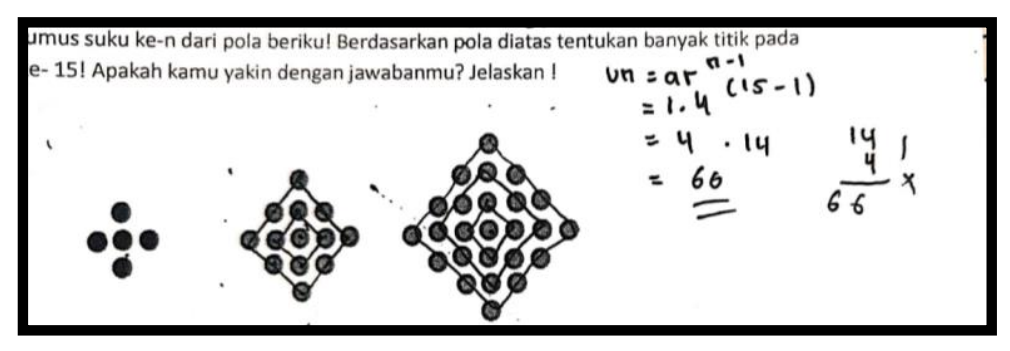

Figure 3. Student work results IA

Figure 3 shows the students' steps in solving question number two. The results of student work can be seen that students do not write down information that is known from the questions given. In addition, students also did not provide information about the conclusions of the questions in the questions. Students who do not write down the information provided show that students have not been able to meet the first reasoning indicator. IA students also do not describe the patterns in the questions so that they are considered unable to fulfill the second reasoning indicator. IA students also do not give general pattern generalizations. Students who choose to use these solutions are considered to know that the questions can be done using the pattern rules so that IA students are considered to fulfill the third indicator. In completing the questions given, IA students have not yet generalized the formula. The inability of students to make generalizations makes students considered unable to meet the fifth, sixth, and seventh indicators. 
The results of the interview were then analyzed to see the students' argumentative abilities to show the reasoning process carried out in solving the questions given. Based on the results of the argumentation analysis carried out, IA students have not been able to provide accurate claims for solutions to the solution steps and the final results of the questions. When the interview process took place students were able to state the data used as the basis for students to make claims. This ability shows that IA students are able to analyze mathematical situations so that they are able to provide relevant data to support claims. The reasons and assumptions given by students are partly sufficient to support the claims, but students cannot determine the limits that can strengthen the claims given. Students are also unable to provide rebuttals to defend their claims. These results show that students are only able to assume and provide reasons for the assumptions given but have not been able to understand the material given properly. Students do not understand the material presented when they are not able to set boundaries and express rebuttals in the argumentation process. The results of the interview showed that students did not carry out the reasoning process in doing the questions well. Students only remember formulas that they have ever known without knowing the use of these formulas. Students do not reason well in solving problems even though students are able to state the information data known in the questions. Based on the description of the analysis results obtained, it is concluded that IA students do not have good reasoning skills in solving the number pattern problems given.

AS students are students who solve question number 2. AS students are classified as having high reasoning abilities based on their work results.

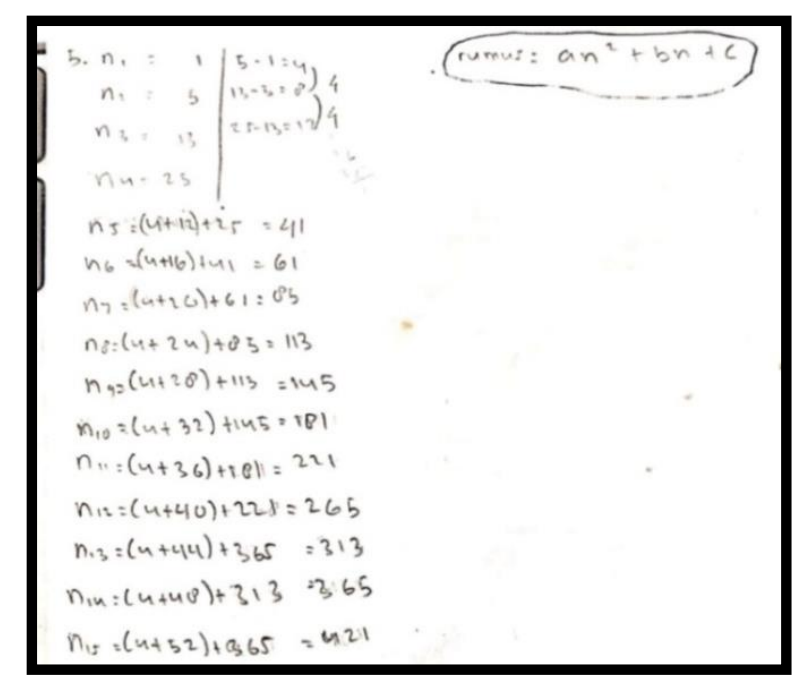

Figure 4. Student work results AS

Based on the results of the interview, an analysis of the arguments given by the students was carried out to show the reasoning process carried out by students and to find out the validity of the 
student's work. The results of the US student interview analysis showed the claims given by the AS students for the solution to the number 2 problem and the final results obtained were correct. These results show that students are able to make claims accurately so that they meet the aspects of the ability to estimate the completion process and provide good conclusions in the process of reasoning. The data used as the basis and support in making claims are relevant and the data are used to support the claims made. This shows the students carry out the reasoning process by analyzing the mathematical situation on the questions well. Assumptions and reasons given by students to be able to explain the relationship between the data and claims made by students. Besides that, the limitations and objections raised by the students are also able to strengthen the claims given. In the solution given, students show the reasoning process inductively. This is indicated by students who analyze the given number patterns. This ability shows students in solving question number 2 are able to provide valid arguments in the reasoning process. However, in solving the problem, the students did not generalize the formula for the problem solution. Students choose to work manually using data that students know. The choice of the solution shows the students reasoning inductively. Based on the results of the students' argumentation analysis descriptions obtained, US students are classified as students with high reasoning abilities based on the results of written tests and their arguments.

Based on the results of the score, student $\mathrm{H}$ is classified as a student who has high reasoning abilities. The following is the student's work in solving question number 3 .

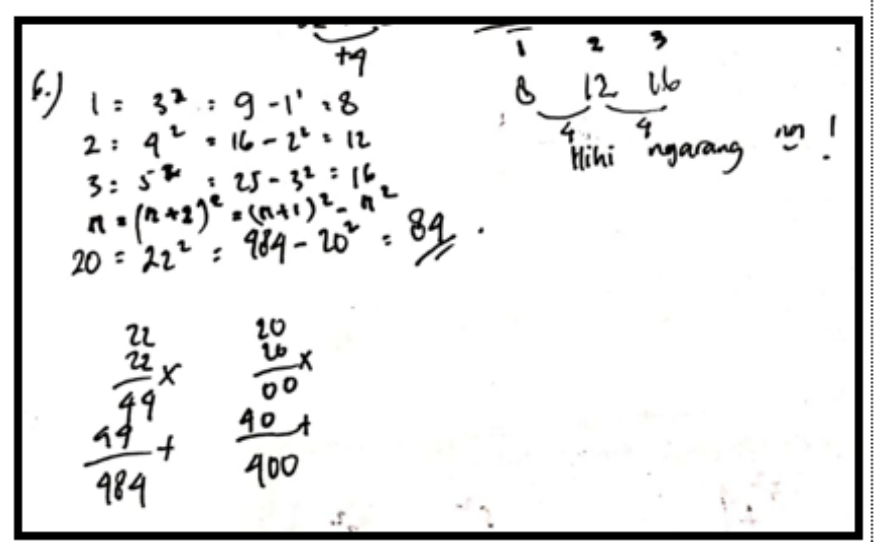

Figure 5. Student work results $\mathrm{H}$

In figure 5 show the results of the arguments obtained from the interview process with student $\mathrm{H}$ were then analyzed to determine the students' process of reasoning. Student $\mathrm{H}$ in the interview gave the correct claim for the final result solution and the step claim to solve the given number pattern problem. The correct claim results prove that students carry out a reasoning process by being able to estimate the steps to solve and the solution to the final results of the questions. Students are also 
able to show the data used as a basis for making a claim that is given. The data provided by students can be used as support for relevant claims showing that students are able to analyze the mathematical situation contained in the questions. The assumptions and reasons given by students when the interview process took place showed that students understood the relationship between the data obtained so that they chose the claim that was given with confidence. This ability shows that students are also able to provide valid arguments to support the results of student analysis in solving questions. In addition to the assumptions and reasons given by students, the ability to make valid arguments is also strengthened by the limitations made by students and rebuttals given by students which strengthen the reasons and assumptions given by students.

The results of the student work analysis and supported by the students' arguments show that students carry out the reasoning process inductively in solving problems. Students choose solutions to describe the data they know and make generalizations for number pattern formulas in general. And based on this description, students $\mathrm{H}$ are classified as having high reasoning abilities seen from the work results and strengthened by their arguments.

AN students are students who have low reasoning skills based on their written test scores. The following is the work of AN students.

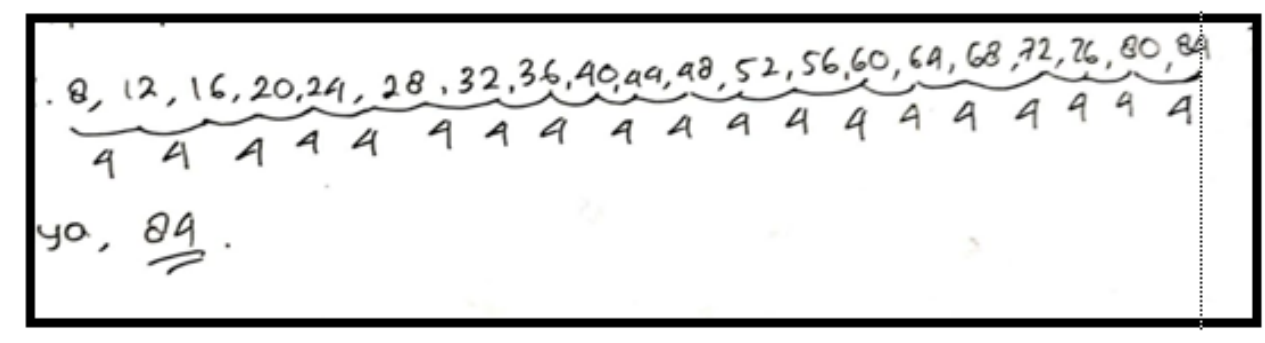

Figure 6. Student work results $\mathrm{H}$

Figure 6 show the student $\mathrm{H}$ results. Based on the results of interviews conducted, students 'arguments were analyzed to determine students' reasoning processes. It can be seen from the results of the interview that AN students were able to make the right claims for the solution to the steps to solve and the final results of the questions. The ability of students to make claims shows that students carry out the reasoning process by fulfilling the aspects of being able to predict the problem-solving process. Partially given data can also show the basis of students in making claims. In addition, the data used by students is also relevant to support the claims given. The assumptions and reasons given are also sufficient to describe students' understanding in relating the data and claims given. The ability of students to provide relevant data and to be able to provide assumptions along with the right reasons shows that students carry out a reasoning process that can be seen from the fulfillment of 
aspects of students' abilities in analyzing mathematical situations on the questions. However, the limitations and arguments given by students have not been able to strengthen claims.

Based on the results of the analysis above, it can be concluded that in solving the questions given the students do inductive reasoning and are classified as having moderate reasoning abilities. In solving the questions, students are able to explain the completion process carried out. Even though students have moderate reasoning abilities, the inability of students to provide rebuttals in the interview process shows students in solving questions are still having doubts.

Based on the results of student work and interviews which showed the results of the analysis of written reasoning abilities with the highest written test scores and low written results and supported by the results of the analysis of students 'arguments, the findings were related to the reasoning abilities possessed by students in terms of students' arguments. The following are the findings of the analysis process:

- Some students with high written reasoning abilities showed that they did the reasoning process well when the interview process took place. This can be seen when students are able to provide assumptions, reasons, limitations, and rebuttals in the student's argument process.

- There are students with high scores of written reasoning abilities, but the arguments made by students cannot explain the answers they get. They cannot provide assumptions, reasons, limitations, and rebuttals to strengthen their work which shows that their reasoning process is lacking.

- Students who have low scores of reasoning abilities tend not to write down information from data that can support answers. However, students were able to explain the data that supported their answers verbally which was seen when students argued during the interview process.

- Based on the interview process that took place, even though the students were not accurate in making claims, there were students who were able to provide the correct data to support the claim for a solution to how to solve the questions given. Students are also able to provide assumptions, reasons, limitations, and rebuttals to strengthen claims for the solutions given, it's just that in the process of calculating students experience difficulties so that the claim answers given are not correct.

Based on the findings of this researcher, there are four conditions of students' mathematical reasoning abilities based on their written abilities and arguments. The first condition is students who have the highest score of reasoning ability and show good reasoning skills in terms of their arguments. From the results of the student argument analysis adjusted to the Toulmin argumentation 
model, the student with the first condition showed that the student made a claim accompanied by the correct data. The student's ability shows that students can estimate the completion process and analyze mathematical situations. In addition, with the abilities possessed by these students, students show that they do reasoning in the process of solving a given mathematical problem. Claims that are accompanied by precise data in the argumentation process that support the results of the written test show their ability to reason more validly. With this ability, students are considered to have mathematical reasoning abilities. The first condition is in accordance with previous research which states, accurate arguments are made to justify their work. can show students do good reasoning [8] [13]. The results of the argumentation analysis of YABF students have good argument skills, indicating that students understand the concept and have the ability to reason well from the number pattern material. Good reasoning skills based on the results of students' good argumentation skills are in accordance with previous research conducted by Handayani and Sardianto which states that good argumentation skills indicate good reasoning skills as well [6].

The second condition is students who have the highest score of reasoning abilities seen from the written test but are unable to provide arguments to account for their work properly. The results of the argumentation analysis reviewed by Toulmin's argumentation model showed students with the second condition were able to take the test in writing, would but in the interview process the students were not able to provide assumptions along with the right reasons to support the claims given. The inability of students to provide assumptions along with these reasons indicates that students do not understand the material given. The results of the arguments produced by the students show that students have not made reasoning in the process of solving the questions. In the process of solving questions, students only follow the examples given by the teacher and do not understand the concepts given. The second condition is in accordance with the results of previous research which shows that students' arguments encourage students to show evidence in the process of reasoning so that they can solve problems [6] [11]. Students who do not understand the concept tend to experience difficulty in analyzing mathematical situations which results in students also having difficulty in reasoning. This condition shows that there are conditions that students with the highest reasoning skills in the written test have less reasoning abilities [2]. This second condition is in accordance with the problems encountered in previous research which encountered students with good written skills but did not understand the concept and did not carry out the reasoning process in solving the questions given [6].

The third condition is students with low scores of reasoning abilities as seen based on the results of students' written tests but have good argumentative skills based on the Toulmin argumentation 
model. This condition shows that even though students have not been able to write information in writing on the worksheet, students are able to express their reasoning skills when expressing arguments. This condition is in accordance with Suhendra's research which states that students have good reasoning abilities, but have not been able to write in work results and do not have the opportunity to express their opinions verbally so that students are considered to have poor reasoning skills [11]. The data provided by the students in their arguments in this study shows the ability of students to analyze the mathematical situation in the questions. The assumptions and reasons given by students to strengthen the claims given are also able to explain that students understand the concept of the number pattern material. those who are able to provide arguments by showing the reasoning abilities possessed by the subject used in solving the problems given are also good. The arguments given by students also show that students understand the concept well so that they are able to support students in reasoning. This condition is in accordance with the conditions found in previous research which explains, students who have good reasoning skills but have not been able to write them in a worksheet properly [6] [11].

The fourth condition is the students' reasoning ability which is classified as low as seen from the written test score and has less argumentative skills. In this condition the students have difficulty in solving the questions given. In the written test, students showed that they were not able to write down the information contained in the questions and in the interview process the arguments given by the students were also unable to provide the data needed to strengthen the claims given. This shows that students have not been able to analyze mathematical situations in the process of reasoning. In students with the fourth condition, students are also less able to show their assumptions and reasons in determining the claims made. The inability of students to provide assumptions and reasons shows that students have not been able to provide valid arguments in the reasoning process. In addition, the inability of students to show assumptions and reasons also shows that students have not understood the concept of number pattern material and have not carried out the reasoning process properly. Students only carry out the process according to what they have learned without believing that the method given is correct. The fourth condition is in accordance with the research conducted by Handayani, Sardianto and Rosita who found students' mathematical reasoning problems which were shown by students who were less able to write their work and were unable to explain their answers in the interview process [6] [9]. 


\section{Conclusion}

Based on these results, the arguments raised by students can help prove students' mathematical reasoning abilities validly. Argument analysis adapted to the Sthepen Toulmin argumentation model can bring out a picture of the student's reasoning process as a whole.

This is indicated by two conditions, namely students who are considered capable of reasoning as seen from the written results but do not prove the verbal reasoning process and students who are considered to lack written reasoning skills but are able to demonstrate the process of reasoning orally. This condition has not been able to be obtained when only looking at the results of students' written tests. Based on these results, the arguments raised by the students adapted to the Toulmin argumentation model can help prove students' mathematical reasoning abilities validly. The argumentation analysis adjusted to the Sthepen Toulmin argumentation model can bring out a picture of the overall reasoning process of students as follows: 1) Students who have good reasoning skills are shown by good written test score results and good argumentation, 2) Students who have good ability scores reasoning is good in written tests but is less able to provide arguments to strengthen the results of solving the questions given. This shows the students' lack of reasoning ability, 3) Students who have reasoning abilities as seen from the written test results are less but students are able to provide arguments that show the student's process of reasoning in determining the problem solving. This condition shows that students have good reasoning skills and 4) Students with written reasoning skills are lacking and also have not been able to provide good arguments to show the students' process of reasoning. This shows the students' lack of reasoning ability.

\section{Acknowledgment}

Researchers would like to thank Mr. Susiswo and Mr. Tjang Daniel Chandra were always the lecturers who guided researchers in this research and the students of SMP Aisyiyah who had participated became the subjects in this study

\section{References}

[1] Battista, M. T. (2017). Mathematical Reasoning and Sense Making in Grades 6-8 1, 1-24.

[2] Çınar, D., \& Bayraktar, Ş. (2014). Evaluation of the Effects of Argumentation Based Science Teaching on 5 th Grade Students ' Conceptual Understanding of the Subjects Related to "Matter and Change," 2(1), 49-77.

[3] Dwi, N., Devi, C., Vh, E. S., \& Indriyanti, Y. (2018). Analisis Kemampuan Argumentasi Siswa SMA pada Materi Larutan Penyangga. JKPK, 3(3), 152-159. 
[4] Eibensteiner, J. L. (2012). Conceptual and Procedural Knowledge Community College Students Use When Solving Science Problems, 169-178. https://doi.org/10.1080/10668920802134982

[5] Faruq, A. (2014). Analisis Struktur Argumentasi dan Kemampuan Mengkontruksis Bukti Matematika Siswa Sekolah Menengah, 13-27.

[6] Handayani, P., \& Sardianto, M. S. (2015). Analisis Argumentasi Peserta Didik Kelas X SMA Muhammadiyah 1 Palembang dengan Menggunakan Argumentasi Toulmin. Jurnal Inovasi Dan Pembelajaran Fisika, 2, 60-68.

[7] Jalali, Z., Ikram, W., \& Syahrinawati, K. A. (2018). Analisis Kemampuan Penalaran Siswa Kelas VIII dalam Menyelesaikan Soal Teorema Phytagoras, (December 2016).

[8] NCTM. (2000). Principles and Standards for School Mathematics. United States of America : The National Council of Teachers of Mathematics, Inc.

[9] Rosita, C. D. (2008). Kemampuan Penalaran dan Komunikasi Matematis: Apa, Mengapa, dan Bagaimana Ditingkatkan pada Mahasiswa, 1(1), 33-46.

[10] Safrida, L. N., As'ari, A., \& Sisworo. (2016). Pengembangan Perangkat Pembelajaran Berbasis Problem Solving Polya Untuk Meningkatkan Kemampuan Penalaran Matematis Siswa Materi Peluang Kelas XI SMA, 583-591.

[11] Suhendra. (2010). Argumentasi Matematik Sebagai Sebuah Kompetensi MAtematik. Jurnal Pengajaran MIPA, 15(1), 1-3.

[12] Sunarno, W., \& Prasetyo, Z. K. (2016). Pemberdayaan Keterampilan Argumentasi Mendorong Pemahaman Konsep Siswa, 7(April), 43-48.

[13] Toulmin, S. E. (2003). The Uses Argument. New York: Cambridge University Press. 